\title{
Assessment of Knowledge, Attitude and Practice of Graduating Health Science Students towards Blood Donation at Wolaita Soddo University
}

\section{Obsa $\mathrm{MS}^{1^{*}}$, Weji BG ${ }^{1}$, Dedecho $\mathrm{AT}^{2}$ and Worji $\mathrm{TA}^{2}$}

${ }^{1}$ Department of Anesthesia, School of Medicine, Wolaita Sodo University, Wolaita Soddo, Ethiopia

${ }^{2}$ Department of Anesthesia, School of Medicine, Arsi University, Asella, South East, Ethiopia

"Corresponding Author: Obsa MS, Department of Anesthesia, School of Medicine, Wolaita Sodo University, Wolaita Soddo, Ethiopia, Tel: +251910762476/+251947329705; Fax: +251465515113; E-mail: msuleiman43@yahoo.com

Received date: Feb 04, 2018; Accepted date: May 21, 2018; Publish date: May 30, 2018

Copyright: $\bigcirc 2018$ Obsa MS, et al. This is an open-access article distributed under the terms of the Creative Commons Attribution License, which permits unrestricted use, distribution, and reproduction in any medium, provided the original author and source are credited.

\begin{abstract}
Background: Adequate quantity of blood is considered necessary to receive adequate oxygen and nutrients and to carry out certain function. A huge volume of blood can be lost as a result of various medical, obstetrics or surgical emergency. The aim of this study was assess knowledge, attitude and practice of graduating health science students towards blood donation at Wolaita Soddo University from October 2 to 10, 2017.
\end{abstract}

Methods and Materials: Cross sectional study design was conducted. All selected graduating health science students were included. Regular supervision and follow up was made. Data was entered into Epi info version 7 and was transported to SPSS version 20 for analysis. Descriptive statistics were used to determine magnitude of knowledge, attitude and practice towards blood donation.

Result: A total of 96 graduating health science students were included. Most of the participants were male. The overall knowledge on blood donation among respondents was $75.26 \%$. Highest percentage of study participants agree that blood donation cannot affect health of donors. It was also found there were poor practices of blood donation.

Conclusion and Recommendation: In this study, there were high knowledge and attitude towards blood donation. However, there was a poor practice of donating blood. Therefore, it is very important to promote blood donation practices.

Keywords: Knowledge; Attitude; Practice; Blood donation

Abbreviations: NRVBD: Non-Remunerated Voluntary Blood Donor; VBD: Voluntary Blood Donor; WHO: World Health Organization

\section{Introduction}

Blood is an invaluable liquid. Adequate quantity of blood is needed by the cells of the human body to obtain sufficient oxygen and nutrients and to carry out certain function [1]. Blood transfusion is the shift of blood or blood components from the donor into the bloodstream of the recipient to advance the life expectancy and quality of life in patients with a various conditions [2].

Donation of the blood is charitable action which is drained willingly to save the life of the patient $[3,4]$. This is mainly significant for individuals who have lost huge amounts of blood because of road traffic accidents, are severely anemic because of different causes, obstetric and gynecological bleeding, surgery and chemotherapy [3]. Besides, children being treated for cancer, premature infants, and children having heart surgery need blood and platelet transfusions to survive [4].

World Health Organization (WHO) suggests all countries to focus on young generation to achieve $100 \%$ non-remunerated charitable blood donation by 2020 . It is also recommended that all countries should be self-supporting in all blood products and all blood donations should be charitable, unspecified, and non-paid. According to 2011 WHO report, 107 million blood donations are collected globally; approximately half of these are collected in the high-income countries where there is $15 \%$ of the world's population. Blood donation rate in high-income, middle-income, and low-income countries was 39.2, 12.5 , and 4.0 donations per 1000 population respectively [5].

Moreover, the require of blood for managing victims has been rising radically due to the complexity and succession of investigational medicine. However, the demand and supply have not been yet welladjusted. Inspite of recommendations by WHO as all blood donations should be charitable and non-paid, replacement and remunerated donors are common throughout Sub-Saharan African countries [6]. Besides, in Sub-Saharan African countries, the requirement for blood transfusions is so high because of maternal morbidity, malnutrition, and a heavy weight of infectious diseases [7].

Like any other African countries, there have been a huge deficiency and injustice of accessing blood in Ethiopia. Even though, the national requirement for blood is between 80,000 and 120,000 units per year, only $43 \%$ of blood is collected [8]. In addition, the percentage of blood collected from VBD (Voluntary Blood Donor) and the average annual blood collection rate are extremely low. African countries have reported that the percentage of Voluntary Non-Remunerated Blood 
Citation: Obsa MS, Weji BG, Dedecho AT and Worji TA (2018) Assessment of Knowledge, Attitude and Practice of Graduating Health Science

Page 2 of 5

Donation (VNRBD) was very low in 44 African countries. In Ethiopia only $22 \%$ of blood is being donated by VBD and the country is classified amongst countries that have least number of VBD [9].

Young graduating health science students are not only potential sources for their ability to donate the blood but also for the information they have on the subject matter which could promote the spread of healthy lifestyles and gaining of greater knowledge about one's own health and contribute to the development of a mature, responsible and public attitude so that they can become future donors and motivators. Thus, the objective of this research was to assess level of knowledge, attitude, and practice towards blood donation among graduating health science students in Wolaita Soddo University.

\section{Methods and Materials}

\section{Study setting}

The data was collected from October 2 to 10, 2017 at Otona Campus of Wolaita Soddo University. It is located at Wolaita Soddo town which managerial city of the zone is Wolaita Zone. There are six main roads connecting Soddo to the other cities, which make it the centre of business. The total population of Wolaita Zone is 1.7 million and out of which 120,000 is the population of Sodo Town. There are three hospitals and seventy health center in Wolaita zone.

\section{Study design}

Cross sectional study design was used.

\section{Source population}

All graduating health science students of Wolaita Soddo University.

\section{Study population}

All graduating health science students of Wolaita Soddo University.

\section{Sampling technique}

Censuses were used to include all available consecutive study participants.

\section{Data collection tools and procedure}

Data was collected using self-administered structured questionnaire and items of attitude section were scored on five point likert scale. Data was collected by 2 degree holder Anesthetist and supervised by one MSc holder Anesthetist.

\section{Data quality assurance}

Pretest was done on 5\% of sample size. Data collectors and supervisors were trained on each items included in the study tools. During data collection, regular supervision and follow up was made.

\section{Data analyzing and processing}

Data was checked manually for completeness and then was coded and entered in to Epi info version 7 computer software by investigators and exported to SPSS version 20 computer program for cleaning and analysis. Descriptive statistics was used to summarize data, tables and figures.

\section{Ethical consideration}

Ethical clearance and approval was secured from ethical review committee, College of health science, Wolaita Soddo University. Informed verbal consent was also secured from every study participant. Confidentiality and anonymity were ensured.

\section{Operational definitions}

Voluntary blood donors: is a person who gives blood based on interest.

Non-remunerated blood donors: is a person who does not receive any payment for the purpose of donating the blood.

\section{Result}

Out of 103 graduating health science students 96 were involved. Most of the participants were male 76 (79.16 Majority of them, $89.58 \%$ were found between $20-25$ age class. The mean age of respondents was 23.24+SD (3.248), (minimum 20 and maximum 29) (Table 1).

\begin{tabular}{|l|l|l|l|}
\hline Variable & Category & Frequency & Percentage (\%) \\
\hline \multirow{2}{*}{ Age } & $20-25$ & 84 & 87.5 \\
\cline { 2 - 4 } & $25-30$ & 12 & 12.5 \\
\hline \multirow{2}{*}{ Sex } & Males & 76 & 79.16 \\
\cline { 2 - 4 } & Females & 20 & 20.83 \\
\hline
\end{tabular}

Table 1: Socio-demographic characteristics of graduating health science students at Wolaita Soddo University from October 2 to $10,2017$.

\section{Knowledge towards blood donation}

The overall knowledge on blood donation among respondents was $75.26 \%$, in which 58.33 of the respondent knows minimum age to start blood donation, 75\% knows the lowest weight for blood donation, $66.67 \%$ knows the lowest hemoglobin level required to donate blood, $89.58 \%$ of students aware about the time gaps between the two blood donation (Table 2).

\section{Attitude towards blood donation}

$58.33 \%$ of all study participants are strongly agreed that blood donation should be voluntary while 4 of them disagree that blood donation should not be voluntary. In addition 64 of them agree that blood donation cannot affect health of donors while 14 of them agree that blood donation can affect the health of donor (Table 3 ). 
Citation: Obsa MS, Weji BG, Dedecho AT and Worji TA (2018) Assessment of Knowledge, Attitude and Practice of Graduating Health Science Students towards Blood Donation at Wolaita Soddo University. J Blood Disord Transfus 9: 400. doi:10.4172/2155-9864.1000400

Page 3 of 5

\begin{tabular}{|c|c|c|}
\hline Variable & Frequency of correct answer & Percentage of correct answer (\%) \\
\hline Lowest age for blood donation & 56 & 58.33 \\
\hline Lowest weight for blood donation & 72 & 75 \\
\hline Lowest hemoglobin level to donate blood & 64 & 66.67 \\
\hline lowest interval between two blood donations & 86 & 89.58 \\
\hline Can cancer patient donate blood? & 58 & 60.42 \\
\hline Can donating blood transmit disease? & 52 & 46.875 \\
\hline Blood donors blood returned to normal within how many times & 43 & 44.79 \\
\hline Which food should be to be taken after blood donation? & 78 & 81.25 \\
\hline Should recipient pay to receive blood? & 94 & 97.92 \\
\hline How many patients should take one unit of whole blood? & 92 & 95.83 \\
\hline How many unit of blood is needed for a single recipient? & 79 & 82.23 \\
\hline Can breastfeeding mother donate blood? & 87 & 90.625 \\
\hline Most necessary blood group & 67 & 69.79 \\
\hline Amount of blood can one person donate at a time? & 58 & 60.42 \\
\hline Screening of donor is necessary & 89 & 92.71 \\
\hline Lowest blood pressure for blood donation & 82 & 85.42 \\
\hline Can a person with fever he donate blood? & 76 & 79.17 \\
\hline Duration of storage for donated blood & 48 & 50 \\
\hline Over all knowledge & 72 & 75.26 \\
\hline
\end{tabular}

Table 2: Knowledge of graduating health science students towards blood donation at Wolaita Soddo University from October 2 to $10,2017$.

\begin{tabular}{|c|c|c|c|}
\hline Variable & Category & Frequency & Percentage (\%) \\
\hline \multirow{3}{*}{ Donating blood on voluntary basis is very important? } & Strongly agree & 56 & 58.33 \\
\hline & Agree & 36 & 62.07 \\
\hline & Disagree & 4 & 41.67 \\
\hline \multirow{4}{*}{ A type of blood donation should be } & Voluntary blood & 78 & 81.25 \\
\hline & Replacement blood & 8 & 8.33 \\
\hline & Paid/professional & 4 & 4.16 \\
\hline & Donation for self & 6 & 6.25 \\
\hline \multirow{3}{*}{ Blood donation can affect your health? } & Yes & 14 & 14.58 \\
\hline & Will not happen & 64 & 66.67 \\
\hline & Not sure & 18 & 18.75 \\
\hline \multirow{2}{*}{$\begin{array}{l}\text { Do you think family blood donation is best for the recipient of the same } \\
\text { family? }\end{array}$} & Yes & 66 & 68.75 \\
\hline & No & 7 & 7.29 \\
\hline
\end{tabular}


Citation: Obsa MS, Weji BG, Dedecho AT and Worji TA (2018) Assessment of Knowledge, Attitude and Practice of Graduating Health Science

Table 3: Attitude of graduating health science students towards blood donation at Wolaita Soddo University from October 2 to $10,2017$.

\section{Practice towards blood donation}

In this study, it was found that most of graduating health science students has not donated blood. The reason for not to donate the blood are as follows: No one asked me to donate $16.67 \%$, I am afraid to donate $21.88 \%$, I am medically unfit $14.58 \%$, Blood donation make me anemic $32.29 \%$ and possibly getting infection $8.33 \%$.It was also found that most of the donors are not regularly donating the blood (Table 4).

\begin{tabular}{|l|l|l|l|}
\hline Variable & Category & Frequency & Percentage (\%) \\
\hline \multirow{4}{*}{ Have you donated blood } & Yes & 16 & 16.67 \\
\cline { 2 - 4 } & No & 80 & 83.33 \\
\hline \multirow{5}{*}{ Reason for not donate blood } & No one asked me & 16 & 16.67 \\
\cline { 2 - 4 } & I am afraid & 21 & 21.88 \\
\cline { 2 - 4 } & I am not interested & 6 & 6.25 \\
\cline { 2 - 4 } & I am medically unfit & 14 & 14.58 \\
\cline { 2 - 4 } & Blood donation make me anemic & 31 & 32.29 \\
\cline { 2 - 4 } & Possibly getting infection & 8 & 8.33 \\
\hline \multirow{2}{*}{ If you are only donated blood? } & Regular donor & 3 & 13 \\
\cline { 2 - 4 } & Not regular donor & 3.12 \\
\hline
\end{tabular}

Table 4: Practice of graduating health science students towards blood donation at Wolaita Soddo University from October 2 to $10,2017$.

\section{Conclusion and Recommendation}

The percentage of graduating health science students who had good knowledge and attitude towards blood donation is high. But, the practice was very low. Therefore, it is very important to create awareness on practicing blood donation.

\section{Competing Interests}

We declared that we had no competing interests.

\section{Authors' Contributions}

MS and AT have contributed to conception, initial design of the study, data acquisition, data entry clerk, data analyses, result interpretation, manuscript development and revision. BG has contributed to initial design of the study, data acquisition, data analyses, result interpretation and manuscript development. Both authors read and approve the final manuscript.

\section{Acknowledgements}

We would like to thank all study participants for their support during data collection. Then, we would like to thank to authors of articles, and on-line information for the valuable works, we have read and cited in our paper.

\section{References}

1. Amatya M (2013) Study on knowledge attitude and practice of blood donation among students of different colleges of Kathmandu Nepal. Int J Pharm Biol Arch 4.

2. Olubiyi SK, Babalola FR, Olubiyi MV, Umar NJ, Ibraheem MA(2014) Knowledge, attitudes and practices of blood donation among adults in Ado-Ekiti, Nigeria. SJMMS 2: 052-057.

3. Urgesa K, Hassen N, Seyoum A (2017) Knowledge, attitude, and practice regarding voluntary blood donation among adult residents of Harar town, Eastern Ethiopia: a community-based study. Journal of blood medicine 8: 13.

4. Asamoah AL, Hassall OW, Bates I, Ullum H (2017) Blood donors' perceptions, motivators and deterrents in Sub-saharan Africa: A scoping review of evidence. Br J Haematol 177: 864-877.

5. Melku M, Terefe B, Asrie F, Enawgaw B, Melak T, et al. (2016) Knowledge, attitude and practice of adult population towards blood donation in Gondar Town, Northwest Ethiopia: A community based cross-sectional study. J Blood Transfus 6: 1-10.

6. Ingale L, Gessese S, Miruts G (2015) Magnitude and factors associated with voluntary blood donation practice among adult mekelle population, north Ethiopia: A community-based cross-sectional study. Journal Hematol Oncol 4: 5-13.

7. Osaro E, Charles AT (2011) The challenges of meeting the blood transfusion requirements in Sub-Saharan Africa: The need for the development of alternatives to allogenic blood. J Blood Med 2: 7.

8. Tapko JB, Sam O, Diarra-Nama AJ (2007) Status of blood safety in the WHO African region: Report of the 2004 survey. Brazzaville: Who regional office for Africa. 2007: 1-25. 
Citation: Obsa MS, Weji BG, Dedecho AT and Worji TA (2018) Assessment of Knowledge, Attitude and Practice of Graduating Health Science Students towards Blood Donation at Wolaita Soddo University. J Blood Disord Transfus 9: 400. doi:10.4172/2155-9864.1000400

Page 5 of 5

9. Bates I, Chapotera GK, McKew S, Van Den BN (2008) Maternal mortality in sub-Saharan Africa: The contribution of ineffective blood transfusion services, BJOG 115: 1331-1339. 